\title{
Indicadores qualitativos do ambiente edáfico e serviços ecossistêmicos em diferentes sistemas de ocupação da terra
}

\author{
João Henrique Constantino Sales SILVA ${ }^{*}$, Alex da Silva BARBOSA², Moisés Bittar de ARAÚJO1, \\ Daniel da Silva GOMES ${ }^{1}$, Alexandre Amadeu Cerqueira de MIRANDA¹ ${ }^{1}$ Italo de Souza AQUINO ${ }^{3}$ \\ ${ }^{1}$ Programa de Pós-Graduação em Ciências Agrárias (Agroecologia), Universidade Federal da Paraíba, Bananeiras, PB, Brasil. \\ ${ }^{2}$ Departamento de Agricultura, Universidade Federal da Paraíba, Bananeiras, PB, Brasil. \\ ${ }^{3}$ Departamento de Ciência Animal, Universidade Federal da Paraíba, Bananeiras, PB, Brasil. \\ *E-mail: joaohenriqueconst@gmail.com \\ (ORCID: 0000-0001-6218-5096; 0000-0002-7343-6134; 0000-0003-4696-254X; 0000-0002-7293-7762; \\ 0000-0002-7358-1235; 0000-0002-7948-8760)
}

Recebido em 13/10/2021; Aceito em 29/11/2021; Publicado em 18/12/2021.

\begin{abstract}
RESUMO: O conceito de sustentabilidade tem levado a pesquisa agropecuária a uma crescente busca de modelos alternativos e sustentáveis para a agricultura, sendo as formas de uso e manejo do solo o ponto de partida determinante para a compreensão da dinâmica do ambiente edáfico e serviços ambientais dos agroecossistemas. Sendo assim, este trabalho teve como objetivo avaliar a qualidade do ambiente edáfico e serviços ecossitêmicos em diferentes sistemas de ocupação da terra, através de indicadores ambientais qualitativos. Foram selecionados indicadores sustentáveis de diagnóstico participativo para avaliar quatro sistemas de ocupação da terra: pastagem, mandala agrícola, sistema agroflorestal (SAF) e mata nativa. O conjunto de dados dos indicadores do solo foi analisado por meio de uma Análise dos Componentes Principais (ACP). O sistema agroflorestal apresenta semelhanças na qualidade do ambiente edáfico e serviços ecossistêmicos quando comparado à área de mata nativa. Recomenda-se que práticas de manejo de conservação do solo sejam adotadas nos sistemas com maior intervenção antrópica, a exemplo da pastagem e mandala agrícola.
\end{abstract}

Palavras-chave: indicadores ambientais; qualidade do solo; manejo; agroecossistemas.

\section{Qualitative indicators of the edaphic environment and ecosystem services in different land occupation systems}

\begin{abstract}
The concept of sustainability has led agricultural research to a growing search for alternative and sustainable models for agriculture, with the forms of land use and management being the determining starting point for understanding the dynamics of the edaphic environment and environmental services of agroecosystems. Therefore, this work aimed to evaluate the quality of the edaphic environment and ecosystem services in different land occupation systems, through qualitative environmental indicators. Sustainable indicators of participatory diagnosis were selected to assess four land occupation systems: pasture, agricultural mandala, agroforestry system and native forest. The data set of the soil indicators was analyzed using a Principal Component Analysis (PCA). The agroforestry system has similarities in the quality of the edaphic environment and ecosystem services when compared to the native forest area. It is recommended that soil conservation management practices be adopted in systems with greater anthropic intervention, such as pasture and agricultural mandala.
\end{abstract}

Keywords: environmental indicators; soil quality; management; agroecosystems.

\section{INTRODUÇÃO}

Durante muito tempo o solo foi considerado como um simples depósito de nutrientes e base de fixação dos vegetais. Assim, o valor monetário dos serviços ecossistêmicos do solo foi calculado apenas com base no valor dos nutrientes e carbono nele estocados. Contudo, o solo abriga um complexo ecossistema, rico em microorganismos e invertebrados, que produz uma variedade de serviços ecossistêmicos, além dos nutrientes nele estocados (ROMEIRO, 2015). Por outro lado, o tema "serviços ambientais" tem despertado o interesse de agricultores, pesquisadores, políticos e da sociedade brasileira em geral. Esse interesse resulta do fato de que o capital natural está se tornando cada vez mais escasso e a abordagem em serviços ambientais busca induzir mudança de paradigmas no manejo de recursos naturais e contribuir para a tomada de decisão de gestores de recursos naturais e formuladores de políticas visando o bem-estar da sociedade (PARRON; GARCIA, 2015).

A conversão de uma paisagem natural para uma de uso agrícola pode impor mudanças em atributos, propriedades e processos do solo e trazer consequências ambientais para a região de sua abrangência (ARCOVERDE et al., 2015). Encontrar um equilíbrio entre a conservação do ecossistema e a produção de bens e serviços de que as sociedades precisam para prosperar é fundamental para o desenvolvimento sustentável em longo prazo de qualquer 
região. No entanto, essa busca é ainda mais urgente para terras tropicais secas, como o semiárido brasileiro (ARAUJO et al., 2021).

Na Mesorregião do Agreste da Paraíba há uma carência de estudos sobre identificação de indicadores de alterações químicas, físicas e biológicas do solo em áreas sob diferentes formas de uso e manejo, tendo como referência o solo sob condições naturais (SILVA et al., 2015). De acordo com esses autores, estudos dessa natureza são importantes, pois podem fornecer um conjunto de informações relevantes, representando um inexplorado potencial para o monitoramento e avaliação da qualidade do ambiente edáfico, bem como fornecer uma melhor compreensão da sustentabilidade dos sistemas de cultivo orgânico, a partir da definição de um conjunto de dados mínimos que possam servir como referência para avaliação e seleção de indicadores de qualidade do solo (SILVA et al., 2015).

A seleção de indicadores é fundamental para a avaliação da qualidade do solo. Um bom indicador deve ser capaz de refletir o funcionamento do ecossistema, identificar as formas de perturbações, ser economicamente viável e ter facilidade de monitoramento (SILVA et al., 2020). Nessa perpectiva, a utilização de indicadores qualitativos da sustentabilidade dos solos e serviços ecossistêmicos (SE) permite diagnosticar com antecedência processos que degradam o solo, preveni-los e recuperá-los. Além disso, é possível visualizar quais recursos naturais estão sendo mais impactados e se há discrepância na prestação de SE quando comparamos sistemas de menor ou maior complexidade ambiental e, após o levantamento dessas informações, usá-las como suporte na tomada de decisões para o adequado manejo dos sistemas (ALARSA et al., 2018; VASCONCELLOS; BELTRÃO, 2018; SILVA et al., 2020).

Diante do exposto, objetivou-se avaliar a qualidade do ambiente edáfico e serviços ecossitêmicos em diferentes sistemas de ocupação e manejo do solo, através de indicadores ambientais qualitativos.

\section{MATERIAL E MÉTODOS}

\section{1. Área de estudo}

O estudo foi desenvolvido em quatro sistemas de ocupação da terra, sendo eles: pastagem, mandala agrícola, sistema agroflorestal (SAF) e mata nativa. Todos os sistemas estão situados no Centro de Ciências Humanas, Sociais e Agrárias (CCHSA) da Universidade Federal da Paraíba (UFPB), Campus III, Bananeiras, Paraíba (Figura 1). O município de Bananeiras ocupa uma área territorial de 258 $\mathrm{km}^{2}$ e está localizado na Mesorregião do Agreste, mais especificamente na Microrregião do Brejo, a uma altitude de aproximadamente de 526 metros, distante $141 \mathrm{~km}$ da capital João Pessoa - PB (IBGE, 2021). O clima da região é classificado como As', (tropical chuvoso) quente e úmido (Classificação de Köppen) e se caracteriza por apresentar temperaturas de 18 a $27{ }^{\circ} \mathrm{C}$ e precipitação média anual de 1.200 a $1.500 \mathrm{~mm}$, com chuvas de outono a inverno, concentradas nos meses de março a agosto (SILVA et al., 2021).

O solo da região é do tipo Latossolo Amarelo Distrófico (SANTOS et al., 2018). A fitofisionomia da região é típica de Brejos de Altitude nordestinos, que segundo Barbosa et al. (2004), são áreas que apresentam microclimas dissociantes do contexto onde estão inseridos (semiárido). A umidade característica dessa região está associada ao efeito orográfico que aumenta os níveis de pluviosidade e diminuem as temperaturas, o que forma "ilhas" de microclima diferenciado; e suas formações florestais são disjunções de floresta atlântica, ilhadas pela vegetação da Caatinga, condição que torna essa região em uma área de elevada biodiversidade.
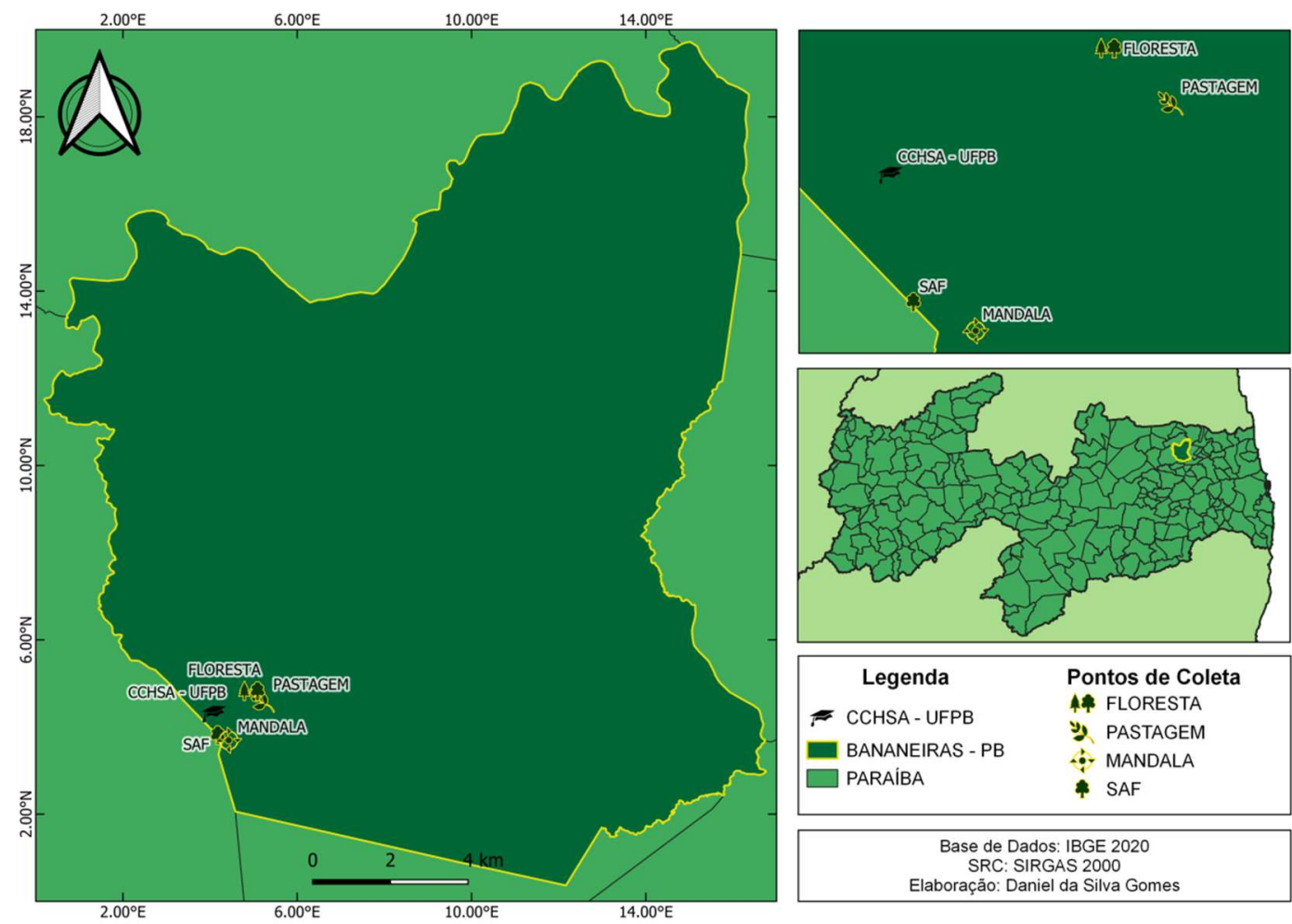

Figura 1. Localização dos sistemas de ocupação da terra no município de Bananeiras, Paraíba, Brasil.

Figure 1. Location of land occupation systems in the municipality of Bananeiras, Paraíba, Brazil. 


\subsection{Caracterização dos sistemas}

Pastagem - Área composta por gramíneas exóticas e nativas não identificadas, algumas herbáceas dominantes, a exemplo da salsa-roxa (Ipomoea asarifolia (Desr.) Roem. \& Schult.), algumas arbóreas esparsas, em sua maioria jaqueiras (Artocarpus heterophyllus Lam.) e pequenos arbustos (Figura 2A). A área possui aproximadamente 1,15 ha e não recebe muitos tratos culturais, exceto pela entrada de máquinas para arar e gradear o solo uma vez ao ano. Houve uma tentativa para recuperar a área com o capim Panicum maximum. No entanto, a área foi rapidamente infestada por plantas invasoras espontâneas. Periodicamente, ovinos da raça Santa Inês forrageiam na área.

Mandala Agrícola - O sistema orgânico de produção em formato circular (Figura 2B) é uma área de aproximadamente 0,38 ha que foi implantada há cerca de 17 anos, na qual é compxosta por frutíferas, a exemplo do mamoeiro e bananeira; culturas anuais - milho, macaxeira, feijão e abóbora; hortaliças - alface, cebolinha, cenoura, beterraba, couve, coentro, pimentão; plantas medicinais e aromáticas manjericão, hortelã; e plantas alimentícias não convencionais (Panc), como a taioba. Há, frequentemente, um aporte considerável de matéria orgânica, proveniente de restos de cultura do próprio sistema e esterco de pequenos ruminantes. Por outro lado, a área é manejada sem muitos critérios técnicos. O sistema é capinado com frequência e irrigado, diariamente, com mangueiras e aspersores, não há o uso sistemático de cobertura morta nos canteiros, sendo que boa parte do solo fica exposto e/ou dominado por plantas invasoras, como a tiririca (Cyperus sp.).
Sistema Agroflorestal - O sistema agroflorestal (SAF) corresponde a uma área com cerca de 0,68 ha. Implantado há aproximadamente 16 anos, possui a gliricídia (Gliricídia sepium (Jacq.) Kunth ex Walp.) como planta principal e o café (Coffea sp.), como planta secundária nas entrelinhas, visto que tratase de uma cultura que apresenta exigência de sombra, característica de espécies de sub-bosque (Figura 2C). O solo da área tem uma fina camada $(3-5 \mathrm{~cm})$ de serapilheira proveniente, sobretudo, da fitomassa da gliricídia e de algumas jaqueiras isoladas. No plantio do café a adubação do solo foi feita com esterco caprino/ovino e superfosfato simples como adubação de cobertura. Inicialmente o sistema era irrigado por gotejamento até a primeira frutificação do cafezal. Os tratos culturais que ocorrem na área são: capina seletiva, poda da gliricídia e a colheita do café.

Floresta - O remanescente de Floresta Ombrófila Aberta, possui aproximadamente 35,5 ha e é considerado um importante fragmento florestal ecotonal de Brejo de Altitude que abriga importantes espécimes autóctones representantes da tipologia vegetal de grande relevância fitogenética e ecológica para o resguardo da fauna e flora local. Dentre as espécies que ocorrem na área destacam-se o jatobazeiro (Hymenaea courbaril L.), pitombeiras (Talisia esculenta (Cambess.) Radlk.), biribas (Eschweilera ovata (Cambess.) Mart. ex Miers) e oiticicas (Licania sp.). O solo da área é coberto por uma espessa camada de serapilheira (Figura 2D). Não há sinais de intervenção antrópica no local, sugerindo, portanto, que a área encontra-se em bom estado de conservação.

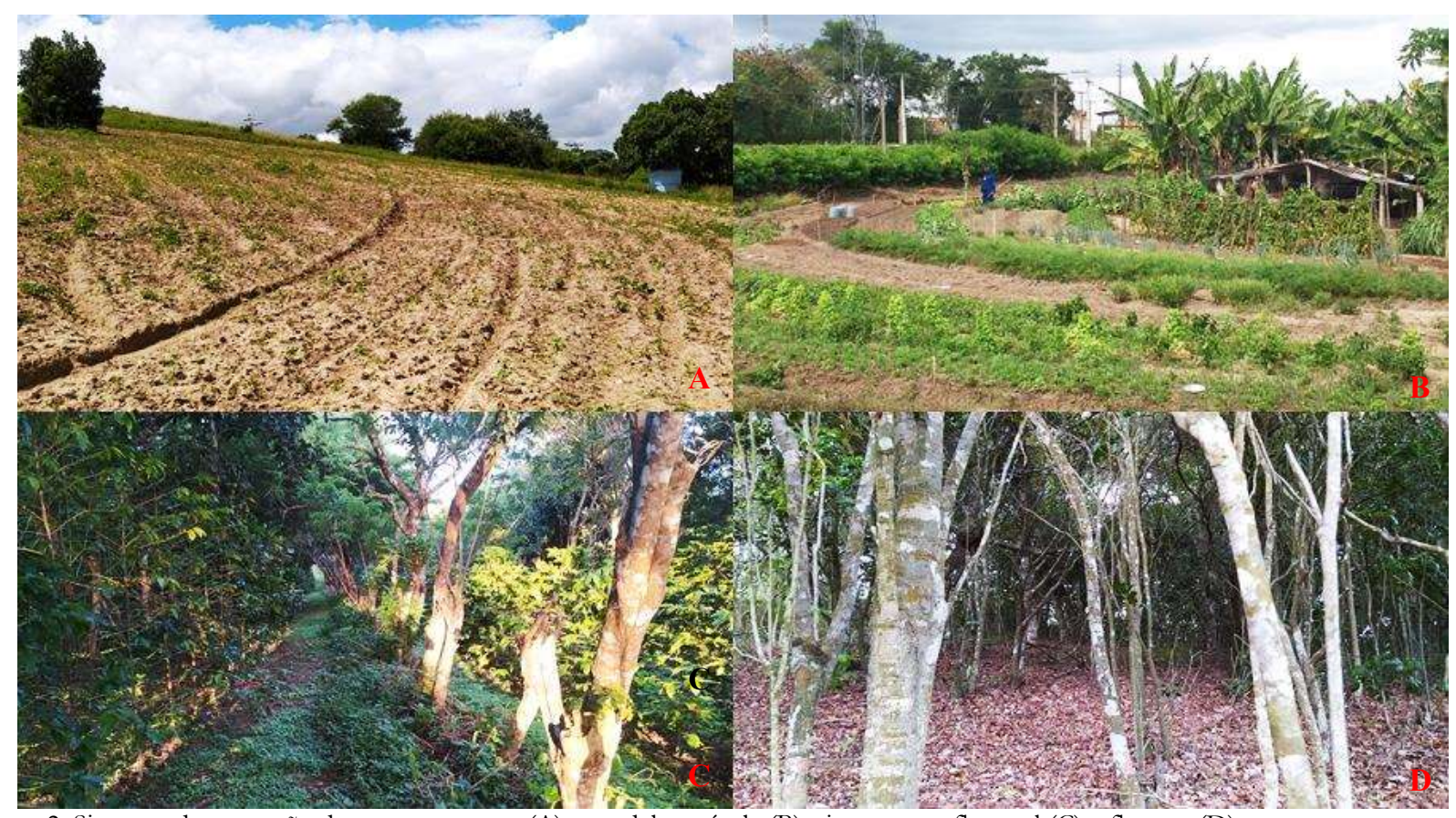

Figura 2. Sistemas de ocupação da terra: pastagem (A), mandala agrícola (B), sistema agroflorestal (C) e floresta (D).

Figure 2. Land occupation systems: pasture (A), agricultural mandala (B), agroforestry (C) and forest (D).

\subsection{Análise qualitativa dos sistemas}

Os indicadores de sustentabilidade utilizados para avaliar os parâmetros qualitativos do ambiente edáfico foram aplicados de acordo com a metodologia proposta por Altieri e Nicholls (2002) e Nicholls et al. (2004) com adaptações, conforme a Tabela 1 , em que para cada característica atribuiu- se um valor de 1 à 10 , com até duas casas decimais. Os valores foram atribuídos por cinco pesquisadores com formação em engenharia agronômica e agroecologia, que realizaram estudos nos quatro sistemas de ocupação da terra, no período compreendido entre 2017-2021, em que avaliaram a qualidade do ambiente edáfico e os serviços ecossistêmicos. 
Os escores foram escolhidos em comum acordo entre os pesquisadores para cada característica e áreas avaliadas. Para a avaliação dos serviços ecossistêmicos prestados por cada sistema de ocupação da terra, foram selecionados seis indicadores de diagnóstico que representam o estado geral do sistema e que respondem aos sinais de sua degradação. Esses indicadores foram: biomassa aérea, aporte de nutrientes no solo, aporte de carbono no solo, abatimento de erosão, evapotranspiração e biodiversidade (VASCONCELLOS; BELTRÃO, 2018).

Tabela 1. Indicadores qualitativos do solo com características e valores correspondentes (valores entre 1 e 10 podem ser atribuídos a cada indicador).

Table 1. Qualitative soil indicators with corresponding characteristics and values (values between 1 and 10 can be assigned to each indicator).

\begin{tabular}{|c|c|}
\hline Indicadores & Caracteríticas \\
\hline Cobertura do solo & $\begin{array}{l}\text { (1) Solo descoberto; } \\
\text { (5) Menos da metade do solo coberto por resíduos, folhas e cobertura viva; } \\
\text { (10) Mais da metade do solo coberto com cobertura viva e morta. }\end{array}$ \\
\hline Compactação e infiltração & $\begin{array}{l}\text { (1) Compacto, fica inundado; } \\
\text { (5) Presença de uma fina camada compacta, a água se infiltra lentamente; } \\
\text { (10) Solo descompactado, a água se infiltra facilmente. }\end{array}$ \\
\hline Retenção de umidade & $\begin{array}{l}\text { (1) Solo seca rápido após a irrigação ou chuva; } \\
\text { (5) Solo permanece seco durante a época seca, umidade limitada que se mantém por pouco tempo; } \\
\text { (10) Solo mantém a umidade na época seca. }\end{array}$ \\
\hline $\begin{array}{l}\text { Cor, cheiro e matéria } \\
\text { orgânica }\end{array}$ & $\begin{array}{l}\text { (1) Solo pálido, com cheiro ruim ou químico, não se observa matéria orgânica; } \\
\text { (5) Solo castanho claro ou avermelhado, com pouco cheiro, e com algum grau de matéria orgânica e } \\
\text { húmus; } \\
\text { (10) Solo com coloração de preto à castanho escuro, com cheiro de terra fresca, se observa abundância } \\
\text { de matéria orgânica e húmus. }\end{array}$ \\
\hline $\begin{array}{l}\text { Suscetibilidade à processos } \\
\text { erosivos }\end{array}$ & $\begin{array}{l}\text { (1) Erosão severa, se nota o arraste do solo, presença de sucos e voçorocas; } \\
\text { (5) Erosão evidente, mas leve; } \\
\text { (10) Sem maiores sinais de erosão. }\end{array}$ \\
\hline $\begin{array}{c}\text { Profundidade e } \\
\text { desenvolvimento de raízes }\end{array}$ & $\begin{array}{l}\text { (1) Subsolo quase exposto, com raízes pouco desenvolvidas, adoentadas, e curtas; } \\
\text { (5) Solo superficial fino, com menos de } 10 \mathrm{~cm} \text {, apresentantando raízes com crescimento limitado e } \\
\text { algumas raízes finas; } \\
\text { (10) Solo superficial mais profundo, com mais de } 10 \mathrm{~cm} \text {, apresentando raízes com bom crescimento, } \\
\text { saudáveis e profundas, com abundância de raízes finas. }\end{array}$ \\
\hline Diversidade vegetal & $\begin{array}{l}\text { (1) Baixa diversidade genética; } \\
\text { (5) Razoável variedade vegetal, com presença de espécies herbáceas e arbustivas com presença de } \\
\text { espécies nativas e exóticas; } \\
\text { (10) Elevada biodiversidade vegetal, com predominância de espécies nativas da região no componente } \\
\text { arbustivo-arbóreo. }\end{array}$ \\
\hline Dinâmica de decomposição & $\begin{array}{l}\text { (1) Presença de resíduos orgânicos que não se decompõem, ou o fazem lentamente; } \\
\text { (5) Ainda há resíduos do ano anterior em processo de decomposição; } \\
\text { (10) Resíduos em vários estágios de decomposição, resíduos velhos bem decompostos. }\end{array}$ \\
\hline Efluxo de $\mathrm{CO}_{2}$ & $\begin{array}{l}\text { (1) Baixa capacidade de sequestrar carbono no solo e elevada capacidade de liberar } \mathrm{CO}_{2} \text { edáfico para } \\
\text { a atmosfera; } \\
\text { (5) Armazena carbono no solo e emite } \mathrm{CO}_{2} \text { edáfico para a atmosfera em igual proporção; } \\
\text { (10) Alta capacidade de sequestrar carbono no solo e baixa capacidade de liberar de } \mathrm{CO}_{2} \text { edáfico para } \\
\text { a atmosfera. }\end{array}$ \\
\hline $\begin{array}{c}\text { Diversidade da macrofauna } \\
\text { epiedáfica }\end{array}$ & $\begin{array}{l}\text { (1) Sem sinais de atividade biológica, não se observam minhocas ou invertebrados (insetos, aranhas, } \\
\text { centopeias, etc.); } \\
\text { (5) Se observam algumas minhocas e artrópodes; } \\
\text { (10) Muita atividade biológica e abundância de minhocas e artrópodes. }\end{array}$ \\
\hline
\end{tabular}

Fonte: Adaptado de Altieri; Nicholls (2002) e Nicholls et al. (2004).

\subsection{Análise química do solo}

Amostras de solo foram coletadas a uma profundidade de 0-20 cm, sendo recolhidas quatro amostras simples em cada sistema. As amostras foram postas para secar a sombra em temperatura ambiente sob a bancada do Laboratório de Análise Físico Química do Solo no CCHSA/UFPB. Em seguida, as amostras foram destorroadas e homogeneizadas para formar uma amostra composta. As análises foram realizadas seguindo a metodologia proposta pela Embrapa (2009). De acordo com a análise, a área de pastagem possui um solo com textura franco arenosa, enquanto que as áreas de remanescente florestal, sistema agroflorestal e mandala possuem uma textura de solo classificada como franco argilo arenosa. Além disso, os solos dos quatro sistemas são relativamente ácidos e os maiores valores de matéria orgânica e carbono orgânico foram encontrados nos sistemas de ocupação floresta, SAF e mandala, respectivamente, enquanto que os menores valores foram observados no solo da pastagem (Tabela 2).

\subsection{Análise estatística}

O conjunto de dados dos indicadores qualitativos do solo foi analisado por meio de uma Análise Multivariada, através de uma Análise dos Componentes Principais (ACP) no software R Studio versão 3.4.1. A ACP é uma técnica que permite o agrupamento de indivíduos similares mediante exames visuais, em dispersões gráficas no espaço bi ou tridimensional, de fácil interpretação geométrica, permitindo, assim, validar ou rejeitar a hipótese de que os indicadores qualitativos do ambiente edáfico são adequados para avaliar os sistemas de uso e cobertura da terra. 
Tabela 2. Atributos químicos dos solos sob diferentes sistemas de ocupação da terra em um Brejo de Altitude no município de Bananeiras, PB.

Table 2. Chemical attributes of soils under different land occupation systems in an Highland Brejo in the municipality of Bananeiras, PB.

\begin{tabular}{|c|c|c|c|c|c|c|c|c|c|c|c|c|c|}
\hline \multirow{2}{*}{ Sistemas } & \multirow{2}{*}{$\begin{array}{c}\mathrm{pH} \\
(1: 2,5)\end{array}$} & $\mathrm{P}$ & $\mathrm{K}^{+}$ & $\mathrm{Na}^{+}$ & $\mathrm{H}^{+}+\mathrm{Al}^{+3}$ & $\mathrm{Al}^{+3}$ & $\mathrm{Ca}^{+2}$ & $\mathrm{Mg}^{+2}$ & SB & СТC & \multirow{2}{*}{$\begin{array}{l}\mathrm{V} \\
\%\end{array}$} & M.O & C.O \\
\hline & & \multicolumn{2}{|c|}{$---\mathrm{mg} \mathrm{dm}{ }^{-3}$} & --- & & \multicolumn{3}{|c|}{$-\mathrm{cmol}_{\mathrm{c}} \mathrm{dm}^{-3}$} & & & & \multicolumn{2}{|c|}{----g kg-1---- } \\
\hline Floresta & 4,99 & 8,59 & 56,82 & 0,83 & 5,19 & 0,10 & 1,83 & 1,80 & 3,85 & 8,06 & 41,26 & 31,36 & 28,09 \\
\hline SAF & 5,55 & 41,87 & 116,91 & 0,04 & 4,41 & 0,05 & 2,70 & 2,78 & 5,84 & 9,56 & 55,94 & 30,27 & 26,07 \\
\hline Mandala & 5,84 & 85,86 & 113,30 & 0,23 & 1,49 & 0,35 & 3,45 & 1,88 & 5,73 & 7,54 & 84,34 & 27,22 & 22,87 \\
\hline Pastagem & 5,61 & 15,75 & 96,30 & 0,01 & 1,64 & 0,10 & 0,98 & 1,75 & 3,00 & 4,14 & 69,59 & 14,39 & 8,65 \\
\hline
\end{tabular}

Legenda: $\mathrm{pH}$, potencial hidrogeniônico; $\mathrm{P}$, fósforo assimilável; $\mathrm{K}^{+}$, potássio trocável; $\mathrm{Na}^{+}$, sódio trocável; $\mathrm{H}^{+}+\mathrm{Al}^{+3}$, acidez trocável; $\mathrm{Al}^{+3}$, alumínio trocável; $\mathrm{Ca}^{+2}$, cálcio trocável; $\mathrm{Mg}^{+2}$, magnésio trocável; $\mathrm{SB}$, soma de bases; CTC, capacidade de troca catiônica; $\mathrm{V} \%$, percentual de saturação por bases; M.O, matéria orgânica; C.O, carbônico orgânico.

\section{RESULTADOS}

Considerando os indicadores qualitativos do ambiente edáfico (Figura 3), percebe-se que o sistema de uso pastagem demonstrou índices de sustentabilidade numa escala de médio a baixo para a maioria dos indicadores, a exemplo da diversidade vegetal, retenção de umidade, efluxo de $\mathrm{CO}_{2}$, cobertura do solo, cor, cheiro e matéria orgânica; enquanto que o SAF apresentou altos índices, assemelhando-se ao sistema de uso floresta. A mandala agrícola, no entanto, apresentou níveis intermédiários, destacando-se entre os sistemas pastagem e SAF. Além disso, depois do sistema de uso floresta, a mandala agrícola ocupa o segundo lugar no quesito diversidade vegetal, devido à riqueza de espécies que são cultivadas na área.

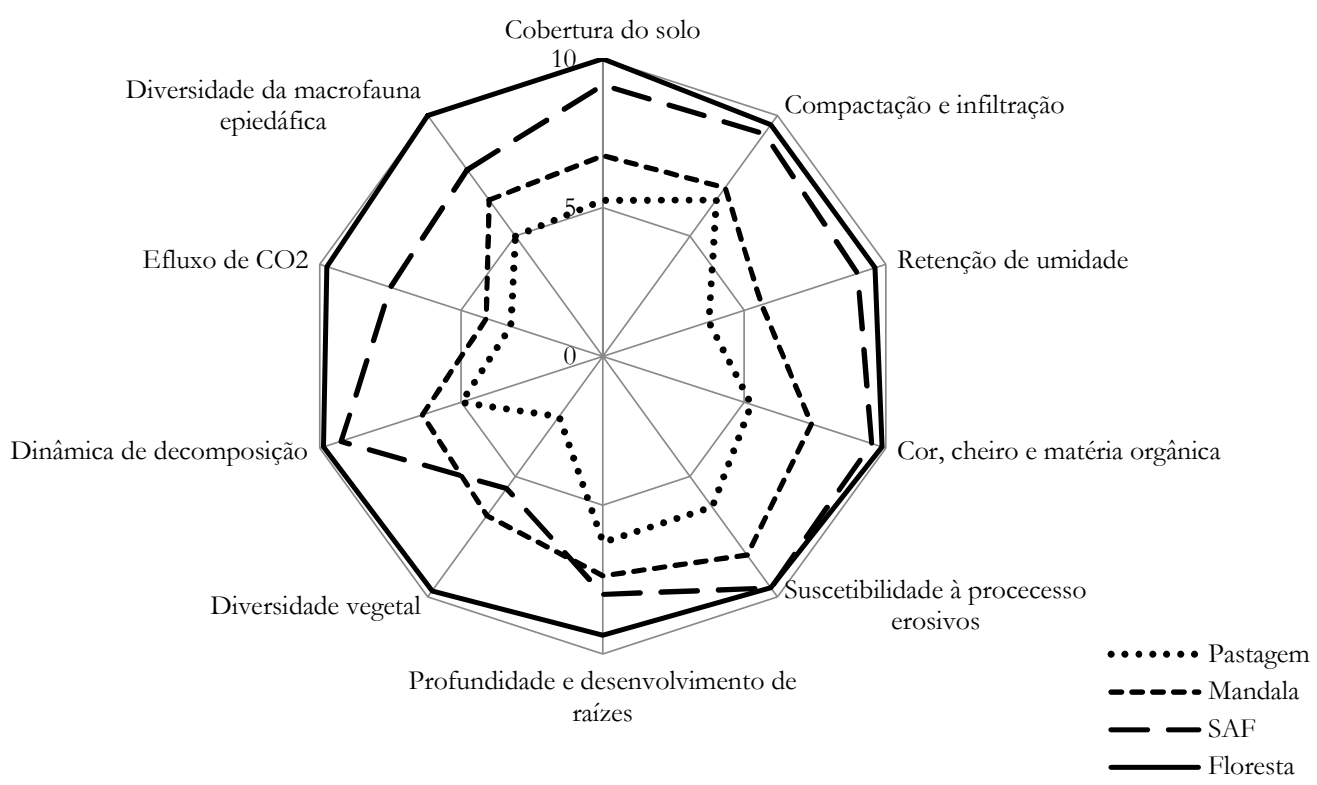

Figura 3. Indicadores qualitativos do ambiente edáfico em sistemas de ocupação da terra no município de Bananeiras, PB.

Figure 3. Qualitative indicators of the edaphic environment in land occupation systems in the municipality of Bananeiras, PB.

Em relação à suscetibilidade a processos erosivos (Figura 3), o sistema de uso pastagem é o mais sucetível, pois apresenta sinais leves de erosão e isso se deve ao fato de que menos da metade do solo da área é coberto por resíduos, como folhas, palhada e cobertura viva, além das características físicas inerentes ao solo da área e o declive do terreno. Considerando os indicadores relacionados à atividade microbiológica dos solos - efluxo de $\mathrm{CO}_{2}$, dinâmica de decomposição, matéria orgânica - nota-se que os sistemas que apresentaram melhores índices de sustentabilidade foram na seguinte ordem descrescente: floresta, SAF, mandala e pastagem (Figura 3).

Quanto aos coeficientes de ponderação e a análise de correlação das características para cada componente principal (Tabela 3), corrobora-se que, quanto maior o valor absoluto do coeficiente, mais relevante será a variável original no componente, ou seja, valores próximos de 1 ou -1 na escala de correlação. Assim, verificou-se que a dimensão 1 abrangeu um maior número de correlação com as características. Nessa mesma perspectiva, observou-se que todas as características se correlacionaram positivamente com o componente principal 1.

Por outro lado, o componente principal 2 facultou uma maior quantidade de correlação negativa, exceto para as características compactação e infiltração, profundidade e desenvolvimento de raízes, efluxo de $\mathrm{CO}_{2}$ e diversidade da macrofauna epiedáfica. Constata-se que os dois componentes principais foram suficientes para explicar mais de $98 \%$ da variabilidade total dos dados de indicadores da qualidade do solo observados nos sistemas de produção sob a influência de seus manejos. Sendo que a CP1 foi capaz de proporcionar uma maior explicação dos dados, externando um percentual de $96 \%$, em contrapartida, a CP2 teve diminuto potencial de explicação, com apenas 2,71\% (Tabela 3). 
Tabela 3. Coeficientes de ponderação e correlação das características para cada componente principal.

Table 3. Weighting and correlation coefficients of characteristics for each principal component.

\begin{tabular}{|c|c|c|c|c|}
\hline \multirow{2}{*}{ Indicadores } & \multicolumn{2}{|c|}{ Componentes } & \multicolumn{2}{|c|}{ Autovetores } \\
\hline & CP1 & $\mathrm{CP} 2$ & C1 & $\mathrm{C} 2$ \\
\hline Cobertura do solo & 0,99 & $-0,003$ & 0,30 & 0,04 \\
\hline Compactação e infiltração & 0,97 & 0,003 & 0,21 & 0,12 \\
\hline Retenção de umidade & 0,99 & $-0,06$ & 0,38 & $-0,03$ \\
\hline Cor, cheiro e matéria orgânica & 0,99 & $-0,14$ & 0,29 & $-0,23$ \\
\hline Suscetibilidade à erosão & 0,96 & $-0,25$ & 0,21 & $-0,34$ \\
\hline Profundidade e desenvolvimento de raízes & 0,95 & 0,25 & 0,18 & 0,20 \\
\hline Diversidade vegetal & 0,97 & $-0,17$ & 0,45 & $-0,57$ \\
\hline Dinâmica de decomposição & 0,99 & $-0,03$ & 0,31 & 0,04 \\
\hline Efluxo de $\mathrm{CO}_{2}$ & 0,97 & 0,19 & 0,40 & 0,59 \\
\hline Diversidade da macrofauna epiedáfica & 0,96 & 0,22 & 0,27 & 0,28 \\
\hline \multicolumn{5}{|l|}{ Autoanálise } \\
\hline Autovalor & 7,21 & 1,21 & & \\
\hline Proporção da variância & 0,96 & 0,02 & & \\
\hline Proporção acumulada & 0,96 & 0,98 & & \\
\hline
\end{tabular}

De acordo com o gráfico biplot (Figura 4), denota-se que as variáveis originais se correlacionaram apenas com sistemas de produção SAF e floresta. As características foram positivamente correlacionadas com esses sistemas sob o ponto visual ponderado pela dimensão 1 (CP). Para o SAF, a característica diversidade vegetal teve maior efeito de interação, por condicionar correlação mais próxima com o sistema. Diante dos resultados apresentados, os indicadores qualitativos do ambiente edáfico direcionaram-se, essencialmente, aos dois sistemas de ocupação da terra SAF e floresta. Assim, isso demonstra que tais sistemas apresentam características ecológicas semelhantes.

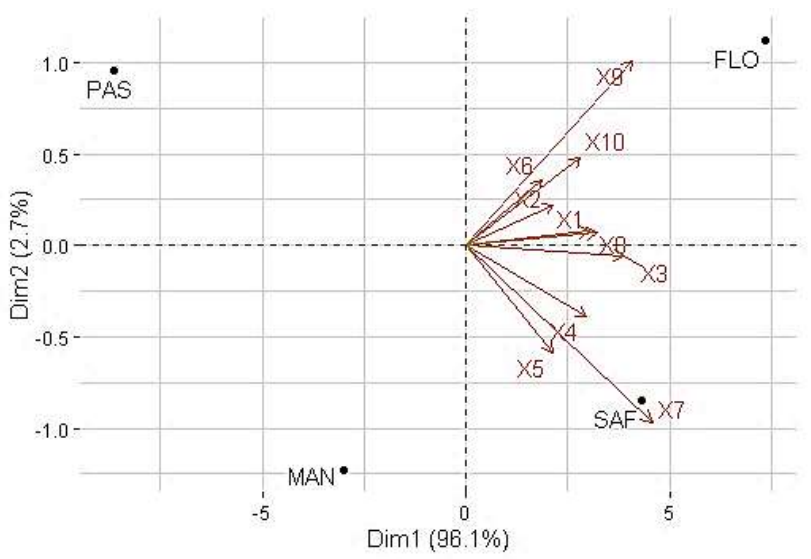

Figura 4. Análise de componentes principais dos indicadores da qualidade do solo em diferentes sistemas de ocupação da terra.

Figure 4. Analysis of main components of soil quality indicators in different land occupation systems.

Sistemas: (PAS) pastagem; (MAN) mandala agrícola; (SAF) sistema agroflorestal; (FLO) floresta. Indicadores qualitativos: (X1) cobertura do solo; (X2) compactação e infiltração; (X3) retenção de umidade; (X4) cor, cheiro e matéria orgânica; (X5) suscetibilidade à erosão; (X6) profundidade e desenvolvimento de raízes; (X7) diversidade vegetal; (X8) dinâmica de decomposição; (X9) efluxo de $\mathrm{CO}_{2}$; (X10) diversidade da macrofauna epiedáfica.

Cabe destacar que estes indicadores estão interligados entre si e não podem ser considerados de forma isolada; ou seja, a suscetibilidade a processos erosivos está associada ao aporte de biomassa da vegetação e a cobertura do solo, que por sua vez está relacionada à profundidade, compactação, infiltração e retenção de umidade, que estão associados à estrutura, textura, teor de matéria orgânica e assim por diante. Isto quer dizer que estes indicadores estão ligados por uma teia ecológica que os fazem interagir entre si, em uma constante troca de energia.

\section{DISCUSSÃO}

Os atributos físico-químicos e microbiológicos do solo são importantes indicadores de alterações causadas por práticas de manejo, sendo a vegetação natural (mata nativa) a referência pedoindicadora ambiental da qualidade do ambiente edáfico (MENDES et al., 2015; FREITAS et al., 2017). Outro importante indicador da qualidade do solo é a diversidade da macrofauna epiedáfica, uma vez que as ações antrópicas, acarretam redução da diversidade e abundância de organismos no solo (HOFFMANN et al., 2018; SUÁREZ et al., 2018; SILVA et al., 2019; PESSOTTO et al., 2020). Nas áreas estudadas foi observada uma maior abundância e diversidade de indivíduos da macrofauna epiedáfica nos sistemas de uso floresta, seguido pelo SAF, mandala e pastagem, nesta sequência.

Faz-se válido destacar que nos sistemas floresta e SAF não há maiores sinais de erosão, provavelmente, devido à presença de serapilheira no solo, ainda que a floresta também se encontre numa área declivosa. $\mathrm{O}$ acúmulo de serapilheira ajuda a retardar e reduzir o escoamento da água da chuva, protegendo o solo e aumentando a rugosidade da superfície (SPLETOZER et al., 2021), bem como a ciclagem de nutrientes.

De acordo com Gomes et al. (2021a; 2021b), a dinâmica de decomposição e o efluxo de $\mathrm{CO}_{2}$ do solo são fortemente influenciados pelas formas de uso da terra e pelos fatores climáticos, a exemplo da precipitação e a temperatura da superfície. Quanto mais carbono houver estocado no solo na forma de matéria orgânica, mais vida haverá no solo, maior será retenção de umidade e mais nutrientes estarão disponíveis para as plantas. Este é um fator importante, pois atualmente é crescente o interesse em promover sequestro de $\mathrm{C}$ em cultivos agrícolas, como uma forma de mitigar o aumento dos níveis de $\mathrm{CO}_{2}$ na atmosfera e, consequentemente, reduzir os impactos causados pelo efeito estufa (SANTOS, 2019). 
Ao se avaliar a prestação de serviços ecossistêmicos (SE) em cada sistema de ocupação da terra (Tabela 4), utilizando o remanescente florestal como referência de elevada prestação de SE, merece destaque o sistema agroflorestal, apresentando elevada prestação de SE para a maioria dos indicadores avaliados, seguido pelo sistema de uso mandala e, por fim, a pastagem. Entretanto, esse último apresentou baixa prestação de SE quando comparado aos sistemas anteriormente citados. É importante destacar que no quesito biodiversidade, a mandala agrícola apresenta elevada prestação de serviços ecossistêmicos. Isso se deve, sobretudo, a riqueza e abundância de espécies (animais e vegetais) que ocorrem nesta área. Segundo Vezzani (2015), há cada vez mais evidências de que os serviços ecossistêmicos são atingidos em função da biodiversidade dos ecossistemas e o papel do solo neste contexto consiste de que a biodiversidade de um ecossistema acontece a partir do ambiente edáfico.

Tabela 4. Prestação de serviços ecossistêmicos por sistemas de ocupação da terra através dos indicadores selecionados.

Table 4. Provision of ecosystem services by land occupation systems through selected indicators.

\begin{tabular}{lcccc}
\hline Serviço & \multicolumn{4}{c}{ Sistema } \\
\cline { 2 - 5 } ecossistêmico & Pastagem & Mandala & SAF & Floresta \\
\hline $\begin{array}{l}\text { Biomassa aérea } \\
\text { Aporte de }\end{array}$ & + & + & ++ & +++ \\
$\begin{array}{l}\text { nutrientes no solo } \\
\text { Aporte de }\end{array}$ & ++ & ++ & +++ & +++ \\
$\begin{array}{l}\text { carbono no solo } \\
\text { Abatimento de }\end{array}$ & + & ++ & +++ & +++ \\
$\begin{array}{l}\text { erosão } \\
\text { Evapotranspiração }\end{array}$ & + & & & \\
Biodiversidade & + & + & +++ & +++ \\
\hline
\end{tabular}

Legenda: (+): baixa prestação de SE; $(++)$ : prestação mediana de SE; e $(+++)$ : elevada prestação de SE.

O solo abriga comunidades microbianas complexas que impactam diretamente os serviços ambientais necessários para a vida na terra, como ciclos biogeoquímicos, trocas gasosas, fixação de carbono, promoção do crescimento vegetal, dentre outras funções ecossistêmicas. A degradação desse recurso representa uma ameaça à segurança alimentar, pois reduz a produtividade, força os agricultores a usar mais insumos e pode, eventualmente, levar ao abandono do solo (GOMIERO, 2016). Assim, as práticas de manejo dos agroecossistemas devem privilegiar aquelas que contribuam para o aumento dos SE, melhorando a sustentabilidade do sistema. Cabe destacar que os SE beneficiam os produtores rurais, por exemplo, a partir da redução e do controle da erosão, conservação dos ciclos da água e de nutrientes, controle biológico de pragas e doenças, aumento do estoque de carbono no solo, polinização, entre outros. Assim, a adoção de práticas agropecuárias ou de sistemas integrados podem proporcionar benefícios in situ e ex situ nas propriedades rurais (PARRON et al., 2019).

Pensar o espaço de forma integrada, considerando seus serviços a partir da susceptibilidade e potencialidades do meio físico e seus atributos da paisagem, é importante para que seja possível o planejamento da ocupação da terra de forma ordenada, partindo da sua capacidade de suporte, das necessidades humanas, e da manutenção da qualidade de vida no tempo e no espaço (ALARSA et al., 2018). Conservar a qualidade da paisagem e mitigar a intensidade do uso da terra é fundamental para aumentar a recuperação da vegetação natural e sua contribuição para a preservação da biodiversidade e dos serviços ecossistêmicos (PÉREZCÁRDENAS et al., 2021).

Os resultados desta pesquisa demonstram que paisagens com complexidade de estrutura intermediária (ou seja, aquelas que combinam vegetação natural e ecossistemas transformados pelo homem), como os SAFs, apresentam semelhanças com áreas de vegetação natural e são eficientes para produzir bens e serviços. Outros estudos apontam as paisagens de maior complexidade ecológica como eficazes para o aumento da biodiversidade nos sistemas produtivos, uma vez que se apresentam como uma alternativa no processo de recuperação de terras degradadas, além de reduzir a perturbação nos ecossistemas e de possibilitar melhorias na renda das famílias envolvidas (VASCONCELLOS; BELTRÃO, 2018; PARRON et al., 2019; ARAUJO et al., 2021; LIMA et al., 2020).

\section{CONCLUSÕES}

As formas de uso e ocupação do solo causam alterações na qualidade do ambiente edáfico e podem repercurtir de forma negativa sobre o estabelecimento de populações ou comunidades e seus processos.

O sistema agroflorestal apresenta semelhanças na conservação da qualidade do ambiente edáfico e serviços ecossistêmicos quando comparado à área de vegetação natural.

Sugere-se que práticas de manejo de conservação do solo sejam adotadas nos sistemas com maior intervenção antrópica, como a pastagem e mandala agrícola, tais como a utilização de adubo verde, cobertura morta e o incremento do componente arbóreo.

\section{AGRADECIMENTOS}

À Coordenação de Aperfeiçoamento de Pessoal de Nível Superior (CAPES) pela concessão de bolsa e auxílio aos pósgraduandos no desenvolvimento da pesquisa.

\section{REFERÊNCIAS}

ALARSA, C.; FURLAN, S. A.; COLANGELO, A. C. Aspectos do meio físico no cenário dos serviços ecossistêmicos. Revista do Departamento de Geografia, Volume Especial do II Workshop do Programa de Pós-Graduação em Geografia Física, p. 184195, 2018.2 DOI: http://dx.doi.org/10.11606/rdg.v0ispe.145793.

ALTIERI, M. A.; NICHOLLS, C. I. Un método agroecológico rápido para la evaluación de la sostenibilidad de cafetales. Manejo Integrado de Plagas y Agroecología, n .64, p. 17-24, 2002. Disponível em:

<http://www.sidalc.net/repdoc/A2039E/A2039E.PD F>. Acesso em: 01 abr 2021.

ARAUJO, H. F. P.; MACHADO, C. C. C.; PAREYN, F. G. C.; NASCIMENTO, N. F. F.; ARAÚJO, L. D. A.; BORGES, L. A. A. P.; SANTOSE, B. A.; BEIRIGO, R. M.; VASCONCELLOS, A.; DIAS, B. O.; ALVARADO, F.; SILVA, J. M. C. A sustainable agricultural landscape model for tropical drylands. Land Use Policy, v. 100, e104913, 2021. DOI: https://doi.org/10.1016/j.landusepol.2020.104913. 
ARCOVERDE, S. N. S.; SALVIANO, A. M.; OLSZEVSKI, N.; MELO, S. B. D.; CUNHA, T. J. F.; GIONGO, V.; PEREIRA, J. D. S. Qualidade física de solos em uso agrícola na região semiárida do estado da Bahia. Revista Brasileira de Ciência do Solo, v. 39, n. 5, p. 1473-1482, 2015. DOI: http://dx.doi.org/10.1590/01000683rbcs20140282

BARBOSA, M. R. V.; AGRA, M. F.; SAMPAIO, E. V. S. B.; CUNHA, J. P.; ANDRADE, L. A. Diversidade florística na Mata do Pau-Ferro, Areia, Paraíba. In: PÔRTO, K. C.; CABRAL, J. J. P.; TABARELli, M. (Orgs). Brejos de altitude em Pernambuco e Paraíba, História Natural, Ecologia e Conservação. Brasília: Ministério do Meio Ambiente, 2004. p. 111-122.

EMBRAPA_Empresa Brasileira de Pesquisa Agropecuária. Manual de análises químicas de solos, plantas e fertilizantes. 2 ed. Brasília: Embrapa Informação Tecnológica, 2009. 627p. Disponível em: <https://livimagens.sct.embrapa.br/amostras/0008313 6.pdf>. Acesso em: 26 nov 2021.

FREITAS, L.; OLIVEIRA, I. A.; SILVA, L. S.; FRARE, J. C. V.; FILLA, V. A.; GOMES, R. P. Indicadores da qualidade química e física do solo sob diferentes sistemas de manejo. Revista Unimar Ciências, v. 26, n. 1-2, p. 825, 2017. Disponível em: <http://201.62.80.75/index.php/ciencias/article/view/ 511>Acesso em: 26 mar 2021.

GOMES, D. S.; BARBOSA, A. S.; SANTOS, T. M.; SANTOS, S. K.; SILVA, J. H. C. S.; AQUINO, Í. S. Cinética de liberação de $\mathrm{CO}_{2}$ e decomposição da fitomassa em sistemas de uso e manejo do solo. Research, Society and Development, v. 10, n. 1, e9810111413, 2021a. DOI: http://doi.org/10.33448/rsd-v10i1.11413

GOMES, D. S.; SANTOS, S. K.; SILVA, J. H. C. S.; SANTOS, T. M.; SILVA, E. V.; BARBOSA, A. S. $\mathrm{CO}_{2}$ flux e temperatura da superfície edáfica em áreas de caatinga. Revista Brasileira de Geografia Física, v. 14, n. 4, p. 1898-1908, 2021b. DOI: https://doi.org/10.26848/rbgf.v14.4.p1898-1908

GOMIERO, T. Soil degradation, land scarcity and food security: Reviewing a complex challenge. Sustainability, v. $8, \quad$ n. 3 , p. 281, 2016. DOI: https://doi.org/10.3390/su8030281.

HOFFMANN, R. B.; LIMA, S. V.; HOFFMANN, G. S. S.; ARAÚJO, N. S. F. Efeito do uso do solo sobre a macrofauna edáfica. Brazilian Journal of Animal and Environmental Research, v. 1, n. 1, p. 125-133, 2018.

IBGE_Instituto Brasileiro de Geografia e Estatística. Cidades e Estados. Disponível em: $<$ https://cidades.ibge.gov.br/brasil/pb/bananeiras/pan orama>. Acesso em: 8 mar 2021.

LIMA, J. F.; SOUZA, J. B.; BARBOSA, A. S. Sustentabilidade em sistemas produtivos no município de Serraria, Paraíba. Revista Verde de Agroecologia e Desenvolvimento Sustentável, v. 15, n. 1, p. 105-110, 2020. http://dx.doi.org/10.18378/rvads.v15i1.6881

MENDES, I. C.; SOUSA, D. M. G.; REIS JUNIOR, F. B. Bioindicadores de qualidade de solo: dos laboratórios de pesquisa para o campo. Cadernos de Ciência \& Tecnologia, v. 32, n. $1 / 2$, p. 191-209, 2015. DOI: http:/ /dx.doi.org/10.35977/01041096.cct2015.v32.23311.
NICHOLLS, C. I.; ALTIERI, M. A.; DEZANET, A.; LANA, M.; FEISTAUER, D.; OURIQUES, M. A rapid, farmer-friendly agroecological method to estimate soil quality and crop health in vineyard systems. Biodynamics, p. 33-39, 2004. Disponível em: $<$ http://agroecology.pbworks.com/f/biodynindicators.pdf $>$. Acesso em: 28 mar 2021.

PARRON, L.; GARCIA, J. R.; MOREIRA, J. M. M. Á. P.; PORFÍRIO-DA-SILVA, V. Avaliação de serviços ecossistêmicos em sistemas agrossilvipastoris. Revista Iberoamericana de Economía Ecológica, v. 30, n. 1, p. 81-100, 2019.

PARRON, L. M.; GARCIA, J. R. Serviços ambientais: conceitos, classificação, indicadores e aspectos correlatos. In: PARRON, L. M.; GARCIA, J. R.; OLIVEIRA, E. B.; BROWN, G. G.; PRADO, R. B. Serviços ambientais em sistemas agrícolas e florestais do Bioma Mata Atlântica. Brasília, DF: Embrapa, 2015. p. 29-35. Disponível <https://www.alice.cnptia.embrapa.br/handle/doc/102 4082>. Acesso em: 25 mar 2021.

PESSOTTO, M. D. F.; SANTANA, N. A.; JACQUES, R. J. S.; FREIBERG, J. A.; MACHADO, D. N.; PIAZZA, E. M.; ROSA NETO, L.; ANTONIOLLI, Z. I. Relação do uso do solo com a diversidade e a atividade da fauna edáfica. Nativa, v. 8, n. 3, p. 397-402, 2020. DOI: https://doi.org/10.31413/nativa.v8i3.9769

PÉREZ-CÁRDENAS, N.; MORA, F.; ARREOLA-VILLA, F.; ARROYO-RODRÍGUEZ, V.; BALVANERA, P.; FLORES-CASAS, R.; NAVARRETE-PACHECO, A.; ORTEGA-HUERTA, M. A. Effects of landscape composition and site land-use intensity on secondary succession in a tropical dry forest. Forest Ecology and Management, v. 482, e118818, 2021. DOI: https://doi.org/10.1016/j.foreco.2020.118818

ROMEIRO, A. Apresentação. In: PARRON, L. M.; GARCIA, J. R.; OLIVEIRA, E. B.; BROWN, G. G.; PRADO, R. B. Serviços ambientais em sistemas agrícolas e florestais do Bioma Mata Atlântica. Brasília, DF: Embrapa, 2015. p. 20. Disponível em: <https://www.alice.cnptia.embrapa.br/handle/doc/102 4082>. Acesso em: 25 Mar. 2021.

SANTOS, H. G.; JACOMINE, P. K. T.; ANJOS, L. H. C.; OLIVEIRA, V. V.; LUMBRERAS, J. F.; COELHO, M. R.; ALMEIDA, J. A.; ARAÚJO FILHO, J. C.; OLIVEIRA, J. B.; CUNHA, T. J. F. Sistema Brasileiro de Classificação de Solos. 5 ed., Brasília, DF : Embrapa, 2018. 356p.

SANTOS, T. C. S. Impactos das mudanças de uso da terra e manejo nos estoques de carbono do solo em diferentes biomas brasileiros. 69 f. Dissertação (Mestrado em Agronomia) - Centro de Ciências Agrárias, Universidade Federal de Alagoas, Rio Largo, 2019.

SILVA, G. F.; SANTOS, D.; SILVA, A. P.; SOUZA, J. M. Indicadores de qualidade do solo sob diferentes sistemas de uso na mesorregião do agreste paraibano. Revista Caatinga, v. 28, n. 3, p. 25-35, 2015. DOI: https://doi.org/10.1590/1983-21252015v28n303rc

SILVA, J. H. C. S.; AZEREDO, G. A.; TARGINO, V. A.; COSTA, P. M. A. Germinação de sementes de Ceiba speciosa coletadas em Brejo de Altitude. Revista Verde de Agroecologia e Desenvolvimento Sustentável, v. 16, $\begin{array}{lllll}\text { n. } 1, \quad p \quad 97-102, & 2021 . & \text { DOI: } \\ \text { https://doi.org/10.18378/rvads.v16i1.7780 } & \end{array}$ 
SILVA, M. O.; VELOSO, C. L.; NASCIMENTO, D. L.; OLIVEIRA, J.; PEREIRA, D.F.; COSTA, K.D.S. Indicadores químicos e físicos de qualidade do solo. Brazilian Journal of Development, v. 6, n. 7, p. 47838 47855, 2020. DOI: https://doi.org/10.34117/bjdv6n7431

SILVA, R. A.; AGUIAR, A. C. F.; REBÊLO, J. M. M.; SILVA, E. F. F.; SILVA, G. F.; SIQUEIRA, G. M. Diversity of edaphic fauna in different soil occupation systems. Revista Caatinga, v. 32, n. 3, p. 647-657, 2019. DOI: http://dx.doi.org/10.1590/198321252019v32n309rc

SPLETOZER, A. G.; SILVEIRA, L. J.; BARBOSA, R. A.; BARBOSA, S. G.; DIAS, H. C. T. Effect of litter on the surface runoff of a forest fragment in the Atlantic Forest. Revista Brasileira de Ciências Agrárias, v. 16, n. 1, e8597, 2021. DOI: https://doi.org/10.5039/agraria.v16i1a8597

SUÁREZ, L. R.; JOSA, Y. T. P.; SAMBONI, E. J. A.; CIFUENTES, K. D. L.; BAUTISTA, E. H. D.; SALAZAR, J. C. S. Soil macrofauna under different land uses in the Colombian Amazon. Pesquisa Agropecuária Brasileira, v. 53, n. 12, p. 1383-1391, 2018. DOI: http://dx.doi.org/10.1590/s0100204x2018001200011

VASCONCELLOS, R. C.; BELTRÃO, N. E. S. Avaliação de prestação de serviços ecossistêmicos em sistemas agroflorestais através de indicadores ambientais. Interações, v. 19, n. 1, p. 209-220, 2018. DOI: http:/ /dx.doi.org/10.20435/inter.v19i1.1494

VEZZANI, F. M. Solos e os serviços ecossistêmicos. Revista Brasileira de Geografia Física, v. 8, edição especial, p. 673-684, 2015. DOI: https://doi.org/10.26848/rbgf.v8.0.p673-684 